\title{
Gambaran Xerostomia pada Penderita Diabetes Melitus Tipe 2 di Poliklinik Endokrin RSUP. Prof dr. R. D. Kandou Manado
}

\author{
Wulan Grace Walukow \\ Program Studi Kedokteran Gigi, Fakultas Kedoktean Universitas Sam Ratulangi
}

\begin{abstract}
Abstrak
Xerostomia atau mulut kering adalah kondisi yang diakibatkan oleh kurangnya sekresi saliva. Xerostomia itu sendiri muncul pada pasien diabetes melitus yang tidak terkontrol, tidak terdiagnosis, maupun tidak terkontrol dengan baik. Dengan pengertian ini bisa dikatakan bahwa xerostomia merupakan salah satu manifestasi dari diabetes melitus di rongga mulut. Jenis penelitian ini merupakan penelitian deskriptif dan pengambilan sampel dilakukan dengan cara purposive sampling. Penelitian ini dimaksudkan untuk menggambarkan xerostomia pada penderita diabetes melitus tipe 2 di Poliklinik Endorin RSUP Prof. Dr. R. D. Kandou Manado. Dari populasi 108 orang penderita diabetes melitus tipe 2 didapatkan 92 orang $(85 \%)$ mengalami xerostomia dengan kadar gula darah puasa $\geq 100 \mathrm{mg} / \mathrm{dl}$, kadar gula darah 2 jam sesudah makan $\geq 140 \mathrm{mg} / \mathrm{dl}$ dan lama menderita diabetes bervariasi. Sebagai saran dalam penelitian ini, tenaga kesehatan perlu menambah pengetahuan mengenai xerostomia pada diabetes melitus sehingga dapat memberikan pelayanan dan penanganan yang tepat pada penderita, dan penderita diabetes melitus agar lebih memperhatikan kesehatan gigi dan mulut.
\end{abstract}

Kata kunci : xerostomia, diabetes melitus, kadar gula darah, saliva, insulin

Abstract

Dryness of mouth or xerostomia is an condition caused by diminished secretions of saliva. It is occur to uncontrol, not diagnose and not good control diabetes melitus patient, based on the above definitons it can say that xerostomia is an manifestation of diabetes melitus in oral cavity. This research is descriptive research and purposive sampling metode research. The purpose of this research is to describe xerostomia on the diabetes melitus patients in Poliklinik Endokrin RSUP Prof. Dr. R. D. Kandou Manado. The research found that there are 92 patients (85\%) among the 108 population of diabetes melitus type 2 patients has xerostomia with level of fasting blood glucose in $\geq$ $100 \mathrm{mg} / \mathrm{dl}$, post prandial glucose in $\geq 140 \mathrm{mg} / \mathrm{dl}$ and has variety of range xerostomia experience. Consider it is important for health-care professional about need to develop knowledge of xerostomia in associated with diabetes melitus disease to offer good medical management and good patient treatment. The patients also should have good knowledge about care of their dental and mouth health.

Key word : xerostomia, diabetes melitus, level of blood glucose, saliva,insulin.

\section{PENDAHULUAN}

Diabetes melitus (DM) adalah kelompok penyakit metabolik yang dikarakteristikkan oleh tingginya kadar glukosa dalam darah (hiperglikemia) karena kelainan sekresi insulin, kelainan kerja insulin, atau kombinasi keduanya. ${ }^{1,2}$ Diabetes Melitus mempunyai dua tipe utama yaitu DM Tipe 1 (DMT1) yang tergantung insulin (Insulin Dependent Diabetes Mellitus/IDDM) dan DM tipe 2 (DMT2) tidak tergantung insulin (Non Insulin Dependent Diabetes Mellitus/NIDDM). ${ }^{3}$ Pasien yang menderita DMT1 kurang lebih 5-10\% dari seluruh penyandang diabetes selebihnya sekitar 90-95\% pasien diabetes menderita DMT2. ${ }^{4}$ Penelitian epidemiologi menunjukkan adanya kecenderungan peningkatan angka insidensi dan prevalensi DMT2 di berbagai penjuru dunia.
World Health Organization (WHO) memrediksi adanya peningkatan jumlah penyandang diabetes yang cukup besar pada tahun-tahun mendatang serta kenaikan jumlah penyandang DM di Indonesia akan meningkat dari 8,4 juta penderita pada tahun 2000 menjadi sekitar 21,3 juta pada tahun 2030. Indonesia berada di peringkat keempat jumlah penyandang Diabetes Melitus di dunia setelah Amerika Serikat, India, dan Cina. ${ }^{5}$ Populasi DMT2 di Indonesia meliputi 90\% dari semua populasi diabetes. Diabetes melitus tipe 2 dikarakteristikkan oleh adanya hiperglikemia, resistensi insulin, dan adanya pelepasan glukosa hati yang berlebihan. ${ }^{6}$

Prevalensi DM di Sulawesi Utara berdasarkan suatu studi penelitian didapatkan angka $6,1 \%$. Penyakit ini tersebar di seluruh kabupaten dan kota di Sulawesi Utara, dengan prevalensi tertinggi di kota Manado. ${ }^{7}$ Penderita 
DM yang tidak terdiagnosa, tidak terkontrol, ataupun penderita DM yang tidak terkontrol dengan baik akan mengalami manifestasi di berbagai organ termasuk rongga mulut. Rongga mulut penderita DM akan terasa tidak nyaman karena sekresi saliva kurang dari normal dan penderita merasakan mulutnya menjadi kering (xerostomia). ${ }^{8}$ Sekresi saliva normal tanpa stimulasi ialah $\geq 0,3 \mathrm{ml} /$ menit, sedang sekresi saliva normal dengan stimulasi adalah 1-2 $\mathrm{ml} /$ menit. Jumlah sekresi saliva pada orang yang mengalami xerostomia tanpa stimulasi dan dengan stimulasi akan kurang dari 50\% dari angka normalnya sehingga menyebabkan xerostomia. ${ }^{9,10}$

Xerostomia jika dibiarkan dalam jangka waktu yang lama akan menimbulkan berbagai komplikasi pada rongga mulut, seperti gingivitis diabetika, periodontitis, kandidiasis, angular cheilitis, karies gigi dan sindrom mulut kering, sehingga penderita DM yang mengalami xerostomia akan mengalami ganggguan baik secara fisik maupun psikis ${ }^{11}$. Hal tersebut membuat perawatan xerostomia akibat komplikasi DM sangat penting.

Angka kejadian penderita DM yang terus meningkat dari tahun ke tahun, dapat pula menyebabkan peningkatan xerostomia, sehingga penting sekali dilakukan penelitian untuk pencegahan dan pengelolaan yang tepat.

Tujuan penelitian ini ialah untuk mengetahui gambaran xerostomia pada penderita DMT2 di Poliklinik Endokrin RSUP. Prof. Dr. R. D. Kandou Manado.

\section{METODE PENELITIAN}

Subjek penelitian berjumlah 108 pasien. Pengambilan sampel dilakukan dengan cara purposive sampling, yaitu setiap pasien DM yang datang di Poliklinik Endokrin RSUP Prof. Dr. R. D. Kandou Manado pada saat penelitian dan memenuhi kriteria inklusi diambil sebagai sampel penelitian. Kriteria Inklusi; Pasien yang bersedia untuk di wawancarai mengenai keadaan rongga mulutnya.asien terdiagnosa DM dengan usia 40 tahun atau lebih yang saat penelitian, pasien yang bisa berkomunikasi, kasi dan mendengar dengan baik sehingga bisa dilakukan wawancara.

\section{HASIL PENELITIAN}

Jumlah penderita diabetes melitus (DM) yang telah memenuhi kriteria sampel penelitian di Poliklinik Endokrin RSUP. Prof. dr. R. D. Kandou Manado ialah 108 penderita.

Tabel 1. Distribusi Subjek Penelitian Menurut Jenis Kelamin

\begin{tabular}{lll}
\hline Jenis Kelamin & Frekuensi (n) & $\begin{array}{l}\text { Presentase } \\
(\%)\end{array}$ \\
\hline Laki-laki & 50 & 46 \\
Perempuan & 58 & 54 \\
Total & 108 & 100 \\
\hline
\end{tabular}

Tabel 2. Distribusi Subjek Penelitian Menurut Usia

\begin{tabular}{ccc}
\hline Usia (tahun) & Frekuensi (n) & $\begin{array}{c}\text { Presentase } \\
(\%)\end{array}$ \\
\hline $40-49$ & 19 & 17 \\
$50-59$ & 43 & 40 \\
$\geq 60$ & 46 & 43 \\
Total & 108 & 100 \\
\hline
\end{tabular}

Tabel 3. Distribusi Subjek Penelitian Menurut Ada Tidaknya Xerostomia

\begin{tabular}{lcc}
\hline $\begin{array}{c}\text { Xerostomia } \\
\text { (Mulut Kering) }\end{array}$ & Frekuensi (n) & $\begin{array}{c}\text { Presentase } \\
(\%)\end{array}$ \\
\hline Selalu & 52 & 48 \\
Sering & 40 & 37 \\
Kadang-kadang & 7 & 7 \\
Tidak Pernah & 9 & 8 \\
Total & 108 & 100 \\
\hline Kotal
\end{tabular}

Keterangan : Xerostomia

Tabel 4. Distribusi Subjek Penelitian Menurut Kadar Gula Darah Puasa

\begin{tabular}{ccc}
\hline $\begin{array}{c}\text { Kadar Gula } \\
\text { Darah Puasa } \\
(\mathrm{mg} / \mathrm{dl})\end{array}$ & Frekuensi (n) & $\begin{array}{c}\text { Presentase } \\
(\%)\end{array}$ \\
\hline$>100$ & - & - \\
$100-126$ & 28 & 41 \\
$\geq 126$ & 54 & 59 \\
Total & 92 & 100 \\
\hline
\end{tabular}

Tabel 5. Distribusi Subjek Penelitian Menurut Kadar Gula Darah 2 Jam Sesudah Makan

\begin{tabular}{ccc}
\hline $\begin{array}{c}\text { Kadar Gula Darah 2 } \\
\text { Jam Sesudah Makan } \\
(\mathrm{mg} / \mathrm{dl})\end{array}$ & $\begin{array}{c}\text { Frekuensi } \\
(\mathrm{n})\end{array}$ & $\begin{array}{c}\text { Presentase } \\
(\%)\end{array}$ \\
\hline$>140$ & - & - \\
$140-199$ & 42 & 46 \\
$\geq 200$ & 50 & 54 \\
Total & 92 & 100 \\
\hline
\end{tabular}


Tabel 6. Distribusi Subjek Penelitian Menurut Lama Menderita DM

\begin{tabular}{|c|c|c|}
\hline $\begin{array}{c}\text { Lama } \\
\text { Menderita } \\
\text { (Tahun) }\end{array}$ & Frekuansi (n) & $\begin{array}{c}\text { Presentase } \\
(\%)\end{array}$ \\
\hline 1 & 7 & 8 \\
\hline 2 & 8 & 9 \\
\hline 3 & 9 & 10 \\
\hline 4 & 6 & 7 \\
\hline 5 & 12 & 13 \\
\hline 6 & 13 & 14 \\
\hline 7 & 10 & 11 \\
\hline 8 & 5 & 5 \\
\hline 9 & 3 & 3 \\
\hline 10 & 10 & 11 \\
\hline 11 & 2 & 2 \\
\hline 12 & - & - \\
\hline 13 & 1 & 1 \\
\hline 14 & - & - \\
\hline 15 & 4 & 4 \\
\hline 16 & - & - \\
\hline 17 & - & - \\
\hline 18 & - & - \\
\hline 19 & - & - \\
\hline 20 & 1 & 1 \\
\hline 21 & - & - \\
\hline 22 & - & - \\
\hline 23 & - & - \\
\hline 24 & - & - \\
\hline 25 & - & - \\
\hline 26 & - & - \\
\hline 27 & - & - \\
\hline 28 & - & - \\
\hline 29 & - & - \\
\hline 30 & 1 & 1 \\
\hline Total & 92 & 100 \\
\hline
\end{tabular}

Tabel 7. Distribusi Gejala Subjektif di Rongga Mulut

\begin{tabular}{|c|c|c|}
\hline Gejala Subjektif & $\begin{array}{l}\text { Frekuensi } \\
\text { (n) }\end{array}$ & $\begin{array}{c}\text { Presentase } \\
(\%)\end{array}$ \\
\hline Rongga mulut terasa & & \\
\hline kering nyeri dan & & \\
\hline $\begin{array}{l}\text { terbakar pada lidah } \\
\text { dan mukosa }\end{array}$ & 32 & 35 \\
\hline $\begin{array}{l}\text { Kesulitan mengunyah } \\
\text { makanan }\end{array}$ & 20 & 23 \\
\hline Kesulitan menelan & 21 & 22 \\
\hline $\begin{array}{lr}\text { Rasa haus yang } \\
\text { menjadikan } & \text { sering }\end{array}$ & & \\
\hline $\begin{array}{l}\text { minum } \\
\text { Kesulitan memakai }\end{array}$ & 16 & 17 \\
\hline gigi tiruan lepasan & 3 & 3 \\
\hline Total & 92 & 100 \\
\hline
\end{tabular}

\section{PEMBAHASAN}

Mulut kering atau xerostomia adalah keluhan yang paling sering dirasakan oleh penderita DM yang tidak terkontrol, tidak tediagnosa, tidak terkontrol dengan baik dengan adanya penurunan saliva. $^{12,13}$

Penelitian yang dilakukan pada 108 penderita DMT2 di Poliklinik Endokrin RSUP. Prof. dr. R. D. Kandou Manado, didapatkan 52 penderita mengeluh "selalu" merasakan mulutnya kering, dan 40 penderita "sering" merasakan mulutnya kering. Berdasarkan diagnosa subjektif xerostomia pasien yang mengeluh "selalu" dan "sering" merasakan mulutnya kering digolongkan menjadi xerostomia. Dengan demikian, jumlah penderita DMT2 yang mengalami xerostomia di Poliklinik Endokrin RSUP. Prof. dr. R. D. Kandou Manado ialah 92 penderita (Tabel 3).

The Oral Health Science Institute University of Pittsburgh telah melakukan studi epidemiologi pada 406 penderita DMT1 dan 268 DMT2 untuk melihat adanya hubungan antara kesehatan mulut dan diabetes, hasil penelitian tersebut melaporkan pada penderita DM hampir separuhnya merasakan xerostomia. ${ }^{3,2}$ Penelitian yang sama juga ditemukan di Amerika Serikat dari seluruh populasi penelitian, $40 \%$ mengalami xerostomia. ${ }^{14}$

Pemeriksaan kadar glukosa darah dilakukan dengan tujuan untuk mengetahui apakah sasaran terapi telah dicapai dan untuk melakukan penyesuaian dosis obat, bila belum tercapai sasaran terapi. ${ }^{2}$ Penelitian yang dilakukan pada 92 penderita DM yang mengeluhkan xerostomia, didapatkan yang mempunyai kadar gula darah puasa sedang (100$126 \mathrm{mg} / \mathrm{dl})$ ialah 38 penderita $(41 \%)$, yang mempunyai kadar gula puasa buruk $(\geq 126 \mathrm{mg} / \mathrm{dl})$ ialah 54 penderita (59)\% dan yang mempunyai kadar gula darah puasa baik (>100) tidak ada (Tabel 4). Penelitian selanjutnya menggambarkan hal yang sama yaitu dari 92 penderita DM yang mengeluhkan xerostomia, mempunyai kadar gula darah 2 jam sesudah makan sedang (140-199mg/dl) ialah 42 penderita (46\%), yang mempunyai kadar gula 2 jam sesudah makan buruk $(\geq 200 \mathrm{mg} / \mathrm{dl})$ ialah 50 penderita (54)\%, dan mempunyai kadar gula darah 2 jam sesudah makan baik (>100) tidak ada (Tabel 5).

Hasil penelitian ini memperlihatkan bahwa penderita DM yang mengalami xerostomia mempunyai kadar gula darah di atas $100 \mathrm{mg} / \mathrm{dl}$ untuk kadar gula darah puasa dan di atas $140 \mathrm{mg} / \mathrm{dl}$ untuk kadar gula darah 2 jam sesudah makan. Berdasarkan hasil penelitian ini maka dapat dikatakan semakin tinggi kadar gula darah penderita DMT2, semakin tinggi pula kemungkinannya untuk 
merasakan xerostomia. Hal yang sama dikatakan Nasution, bahwa pada penderita DM dengan kadar gula darah yang tinggi (hiperglikemia) dapat menimbulkan kelainan pada rongga mulut salah satunya ialah xerostomia. ${ }^{15}$

Penelitian yang dilakukan Kartimah menjelaskan penyebab terjadinya xerostomia pada DM. Menurutnya, xerostomia pada DM terjadi karena gangguan kongenital neuropati atau karena adanya kerusakan pada nervus kranial VII (nevus fasialis) dan nervus kranialis IX (nervus glosofaringeal) yaitu nervus yang menginervasi kelenjar parotis (69\%) sumber penghasil saliva. ${ }^{10}$

Penelitian mengenai lama menderita didapatkan prevalensi DM dari 92 penderita DMT2 di Poliklinik Endokrin RSUP. Prof. dr. R. D. Kandou Manado bervariasi. Penderita DMT2 yang mengalami xerostomia ialah $\geq 1$ tahun, dengan prevalensi tertinggi pada 5-7 tahun, ada 1 penderita yang telah terdiagnosis DM selama 20 tahun dan 1 penderita yang telah terdiagnosis DM selama 30 tahun (Tabel 6).

Semakin lama pasien menderita DM dengan kondisi hiperglikemia, maka semakin tinggi kemungkinan untuk terjadinya komplikasi kronik. ${ }^{16}$ Komplikasi kronik ini salah satunya adalah xerostomia. Penelitian yang dilakukan Tarigan mengemukakan, bahwa manifestasi penderita DM pada mulut mempunyai bentuk yang bermacammacam tergantung pada kebersihan mulut, lamanya menderita DM dan beratnya DM tersebut. ${ }^{17}$

Penelitian berdasarkan lama menderita DM menunjukkan bahwa semakin lama pasien menderita DM, semakin besar pula kemungkinannya merasakan xerostomia. Hal ini di dukung oleh teori yang menyebutkan lama menderita DM berkaitan dengan terjadinya xerostomia, karena adanya perubahan atropi pada kelenjar saliva sesuai dengan pertambahan umur yang akan menurunkan produksi saliva dan mengubah komposisinya. Seiring dengan meningkatnya usia, terjadi proses aging. Terjadi perubahan dan kemunduran fungsi kelenjar saliva, dimana kelenjar parenkim hilang dan akan digantikan oleh jaringan ikat dan lemak. Keadaan ini mengakibatkan pengurangan jumlah aliran saliva. ${ }^{18}$

Perubahan atropik yang terjadi di kelenjar submandibula sesuai dengan pertambahan usia juga akan menurunkan produksi saliva dan mengubah komposisinya. ${ }^{19}$

Hasil penelitian selanjutnya menggambarkan distribusi gejala subjektif xerostomia di rongga mulut pada subjek penelitian yang memiliki keluhan xerostomia yaitu sebesar 92 orang. Prevalensi keluhan yang terbanyak di dapatkan ialah rongga mulut terasa kering nyeri dan terbakar pada lidah dan mukosa sebanyak 32 orang $(35 \%)$ dan prevalensi terkecil yang mengeluhkan kesulitan memakai gigi tiruan lepasan sebanyak 3 orang (3\%) (Tabel 7).

Edgar \& Mullane mengemukakan, gejala subjektif xerostomia meliputi keinginan minum meningkat, kesulitan dalam berbicara, kesulitan merasakan makanan, kesulitan mengunyah makanan, kering saat menelan, rasa terbakar pada lidah, sering menenggak air terutama saat makan dan saat tidur dan kesulitan menggunakan gigi tiruan (lepasan). ${ }^{9}$ Kartimah mengatakan, adanya xerostomia pada penderita DM dapat terlihat dengan adanya penurunan aliran saliva, penurunan fungsi kecap, kesukaran mengunyah dan menelan, keluhan rasa sakit pada lidah dan mukosa, serta karies yang dapat menjalar dan kehilangan gigi serta lebih peka terhadap terjadinya radang. ${ }^{10}$

Xerostomia menyebabkan mengeringnya selaput lendir. Mukosa mulut menjadi kering, mudah mengalami iritasi dan infeksi. Keadaan ini disebabkan oleh karena tidak adanya daya lubrikasi dan proteksi dari saliva. Rasa pengecapan dan proses berbicara juga akan terganggu. Kekeringan pada mulut menyebabkan fungsi pembersih saliva berkurang, sehingga terjadi radang dari selaput lendir yang disertai keluhan mulut terasa seperti terbakar. Selain itu, fungsi anti bakteri dari saliva pada penderita xerostomia akan berkurang sehingga menyebabkan timbulnya proses karies gigi. ${ }^{20}$

\section{KESIMPULAN}

Berdasarkan hasil penelitian yang dilakukan dapat di simpulkan:

1. Prevalensi xerostomia pada penderita DMT2 adalah sebesar 92 orang atau $85 \%$.

2. Berdasarkan kadar gula darah puasa, pasien dengan kontrol gula darah sedang (100-125 $\mathrm{mg} / \mathrm{dl})$ dengan 38 penderita $(41 \%)$ dan buruk $(\geq$ $126 \mathrm{mg} / \mathrm{dl})$ dengan 54 penderita (59\%) mengalami xerostomia.

3. Berdasarkan kadar gula darah 2 jam sesudah makan, pasien pasien dengan kontrol gula darah sedang (140-199 $\mathrm{mg} / \mathrm{dl})$ dengan 42 penderita (46\%) dan buruk $(\geq 200 \mathrm{mg} / \mathrm{dl})$ dengan 50 penderita $(54 \%)$ mengalami xerostomia.

4. Berdasarkan lama menderita DM, semakin lama menderita DM semakin besar pula kemungkinan penderita merasakan xerostomia.

5. Gejala subjektif xerostomia yang paling sering di rasakan oleh penderita DMT2 ialah rongga mulut terasa kering, nyeri dan terbakar pada lidah dan mukosa yaitu sebanyak 32 orang (35\%). 


\section{DAFTAR PUSTAKA}

1. American Diabetes Association (ADA). The Uncomplicated Guide to Diabetes Complications. Canada:American Diabetes Association;2002.

2. Perkumpulan Endokrinologi Indonesia (PERKENI). Konsensus Pengelolaan dan Pencegahan Diabetes Melitus Tipe 2 di Indonesia. Jakarta:PB.PERKENI;2011.

3. Ignativicius D, Wolkman M.L. Medical Surgical, Nursing, Criticial Thinking for Collaborative Care. $5^{\text {th }}$ ed. St. Louis:Missouri;2006.

4. Smeltzer SC, Bare BG. Buku Ajar Keperawatan Medikal Bedah Brunner \& Suddarth. Edisi 8. Jakarta:EGC;2002.

5. World Health Organization (WHO). Screening for Type 2 Diabetes. [serial online] 2003 [cited 2013 Ap $\quad 04] \quad$ Avaible from:URL:http://www.who.int/diabetes/publica tions/en/screening_mnc03.pdf.

6. Suyono S. Kecenderungan Peningkatan Jumlah Penyandang Diabetes. Dalam:Soegondo S, Soewondo P, Subekti I, editor. Penatalaksanaan Diabetes Melitus Terpadu. Jakarta:FKUI;2009,h,11-18.

7. Pranoto, A. Diabetes Mellitus di Indonesia, Permasalahan dan Penatalaksanaannya. Surabaya:Pusat Diabetes RSUD Dr SoetomoFK UNAIR.(Abstract)

8. Darby ML, Walsh MM. Dental Hygiene Theroy and practice. Philadelphia: WB Saunders Co.

9. Edgar WM, Mullane DM. Saliva and Oral Health. $2^{\text {nd }}$ ed. Great Britain:Thanet press limeited;1996.

10. Kartimah DS. Xerostomia pada penderita DM karena neuropati diabetika glosofaringeal. J PDGI 2006;56(2):53-100.

11. Ilyas, EI. Olaraga bagi Diabetes. Dalam:Soegondo S, Soewondo P, Subekti I, editor. Penatalaksanaan Diabetes Melitus Terpadu. Jakarta:FKUI;2009,h,69-110.

12. Mealey B. Diabets Melitus. In: Greenberg MS and Glick M, editors. Burket'soral medicine diagnosis \& treatment. Hamilton:BC Decker Inc.p,563-575

13. Moore PA, Guggenheimer J, Etzel KR, Wevant RJ, Orchard T. Type 1 Diabetes Melitus, Xerostomia and Salivary Flow Rates. J Am Dent Assoc 2001;92(3):91-281

14. Diabetes and Dry Mouth. [serial online] 2005 [cited 2013 Jun 11] Available from:URL:http://article-diabetes-and-drymouth.Copy.pdf
15. Nasution, M. Kandidiasis Oral pada Diabetes Melitus. Majalah Kedokteran Gigi 2008;41(3):200-206

16. Zahtamal, dkk. Faktor-Faktor Risiko Pasien Diabetes Melitus. Berita Kedokteran Masyarakat 2007;23(3): 142-147

17. Tarigan, MU. Diabetes Melitus dan Hubungannya dengan Perawatan Kedokteran Gigi Anak. Jurnal Kedokteran Gigi USU 2003;8(1):17-22

18. Hasibuan S. Keluhan mulut kering ditinjau dari faktor penyebab manifestasi dan penanggulannya. [serial online] [cited 2013 Sep 30]

from:URL:http://library.usu.ac.id/download/fkg /fkg-sayuti.pdf

19. Kidd EAM, Bechal SJ. Dasar-Dasar Karies. Jakarta: Penerbit Buku Kedokteran EGC;1992,h,67-70.

20. Bartels CL. Xerostomia Information for Dentists : Helping Patients with Dry Mouth. [serial online] 2010 [cited 2013 Sep 02] Available from:URL:http://oralcancerfoundation.org/dent al/xerostomia.htm 